\title{
Bug busting (wet combing) was less effective than malathion lotion for eliminating head lice in children
}

\author{
Roberts RJ, Casey D, Morgan DA, et al. Comparison of wet combing with malathion for treatment of head lice in the UK: a \\ pragmatic randomised controlled trial. Lancet 2000 Aug 12;356:540-4.
}

\section{QUESTION: Is bug busting (wet combing with a fine toothed comb) as effective as malathion lotion for removing head lice in children?}

\section{Design}

Randomised (allocation not concealed*), blinded (outcome assessors),* controlled trial with follow up at 7 days after completing treatment.

\section{Setting}

24 randomly selected primary schools in an area previously identified to have lice with intermediate resistance to malathion, in North Wales and the UK.

\section{Participants}

81 children who were 3-14 years of age and were identified by school nurses as having live, moving head lice; had not used insecticide lotion in the previous 2 weeks; and had no broken skin on the scalp. The sample included children from the participating schools and siblings at home who met the selection criteria. 72 children $(89 \%)$ (mean age $7.7 \mathrm{y}, 71 \%$ girls) were included in the analyses.

\section{Intervention}

37 children were allocated to bug busting. During a home visit, parents were given a bug buster kit, which included instructions, 2 fine toothed nit combs, 1 normal comb, a plastic cape, and stickers. Parents were to wash the hair, apply lots of conditioner, comb the hair straight, and then use the nit comb to comb out lice until none were found. This process was to be repeated every 3-4 days for 2 weeks; if an adult louse was found after the first session, the treatment course was to be extended by 3 further sessions. 44 children were allocated to $0.5 \%$ malathion lotion (Suleo M [SSL International plc, Oldham, United Kingdom]; Derbac M [SSL International] for asthmatic children). During a home visit, parents were given 1 or more $50 \mathrm{ml}$ bottles of the lotion and were asked to follow the instructions on the boxthat is, wet hair thoroughly down to the roots with lotion, allow it to dry naturally and leave it for 8-10 hours, and repeat the application 7 days later. They were not to use a nit comb.

\section{Main outcome measure}

Presence of live head lice determined by using detection combs and direct observation on dry hair.

\section{Main results}

Analysis was by intention to treat. The mean duration of the bug busting treatment was 17.7 days. At 7 days after completing treatment, more children who received the bug busting treatment had live lice than those who received malathion lotion $(\mathrm{p}<0.001)$ (table).

\section{Conclusion}

In children with head lice, bug busting was not as effective as malathion lotion.

*See glossary.
Source of funding: Wales Office for Research and Development.

For correspondence: Dr RJ Roberts, Department of Public Health, North Wales

Health Authority, Mold CH7 1PZ, Wales, UK.

Fax $+44(0) 1352$ 700043 .

A modified version of this abstract appears in Evidence-Based Nursing.
Malathion lotion v bug busting for treatment of head lice in children $\dagger$

\begin{tabular}{lllll} 
Outcome & Malathion & $\begin{array}{l}\text { Bug } \\
\text { busting }\end{array}$ & RRR (95\% CI) & NNT (CI) \\
$\begin{array}{l}\text { Live lice at } 7 \text { days after } \\
\text { treatment }\end{array}$ & $23 \%$ & $63 \%$ & $64 \%(34$ to 81$)$ & 2 (2 to 6) \\
\hline
\end{tabular}

†Abbreviations defined in glossary; RRR, NNT, and $\mathrm{Cl}$ calculated from data in article.

\section{COMMENTARY}

This real world study by Roberts et al examines a fairly common problem in children. Although the researchers were not blinded to which children received wet combing and which were treated with malathion, the clinical outcome assessors were blinded to treatment assignment.

Not all families were completely compliant with the treatments, but the authors were more interested in the effectiveness of the 2 treatments rather than in the efficacy. The approach was methodologically sound.

Malathion was twice as effective as wet combing. Nevertheless, I cannot agree with the authors' conclusion that UK policy should change because of the study's results. Because almost $40 \%$ of children were cured without malathion, I would try the noninsecticide wet combing approach first, reserving malathion for non-responders. Such an approach would be less costly and might slow down the rate at which head lice are becoming resistant to malathion and other insecticides commonly used in treatment. William Feldman, MD University of Toronto Toronto, Ontario, Canada 